\title{
Optimal coordination and service level of the supply chain in the sharing economy: the perspective of social responsibility
}

\author{
Jie Guo ${ }^{1} \cdot$ Yanli Guo ${ }^{1}$ \\ Received: 12 October 2020 / Accepted: 29 March 2021 \\ (c) The Author(s) 2021
}

\begin{abstract}
The sharing economy has changed people's lives. These changes have accelerated the pace of life and improved the quality of life, but have also had some negative effects. For example, in China, in the supply chain of the takeout delivery platform, the service deliverer often violates traffic rules to shorten the delivery time. This phenomenon has aroused widespread concern in society. From the perspective of sustainable operation of platform enterprises and reducing social risks, this issue is worthy of in-depth study. First, this study analyses the optimal decision-making about pricing and service efforts, then discusses the supply chain coordination mechanism under a revenue-sharing contract, and finds that the platform's service level is related to the efforts of deliverers and the elasticity of demand/service. However, under a traditional revenue-sharing contract, the economic returns are not enough to motivate deliverers to avoid violations of traffic regulations; When the increase of cost caused by the improvement of service level is not fully covered by the revenue sharing from the platform, they have a strong incentive to break the rules even if the optimal coordination can be achieved in the supply chain. Second, this study reconstructs the revenue-sharing contract by adding social responsibility to the objective function of the platform enterprises and designs contingent rewards to regulate behaviours of service deliverers. The results indicate that when the contingent reward factor reaches a certain level, the optimal effort of the service deliverers is constrained within a reasonable range, which can to some extent reduce the occurrence of illegal behaviour. Our findings offer fresh insights on coordination of supply chain in the sharing economy, identify new direction for future research on CSR, and provide managers of platform enterprises with suggestions for regulating the behaviour of partners and balance the economic and social benefits.
\end{abstract}

Keywords Sharing economy · Platform · Corporate social responsibility (CSR) · Supply chain coordination · Optimization · Service efforts

\section{Introduction}

With the development of information technology, the rhythm of people's lives is accelerating gradually, and many sharing platform enterprises have undergone rapid development. However, these platforms have also had many negative effects, for example, the delivery time of deliverers bound by the data in system. They are forced to take risky actions, including traffic violations such as running red lights, going against traffic, and speeding. The personal safety of these

Yanli Guo

yanli.guo@buu.edu.cn

Jie Guo

752716824@qq.com

1 Business College of Beijing Union University, A3 Yanjingdongli, Chaoyang District, Beijing 100025, China deliverers and the social risks are cause for concern. On the other hand, according to recent news reports, deliverers have experienced negative effects, such as having been fined, ${ }^{1}$ crying in elevators, ${ }^{2}$ and being scolded by customers for being late. ${ }^{3}$ These issues have become a matter of concern for society. On September 8, 2020, an article [15] titled Takeaway Driver, Stuck in the System, went viral over the Internet and became a hot topic. The article pointed out that, driven by the algorithm and data in the system to deliver the goods before the time promised by the platform, the deliverer may be in such a hurry that he or she does not obey the traffic rules, which causes certain dangers. For example, in

\footnotetext{
${ }^{1}$ See also: https://xw.qq.com/cmsid/20190410A03OYQ/20190 410A03OYQ00.

${ }^{2}$ See also: https://v.youku.com/v_show/id_XMTkzODkzO DcyNA==.html.

${ }^{3}$ See also: https://baijiahao.baidu.com/s?id=164135122786540 $4643 \& w f r=$ spider $\&$ for $=$ pc.
} 
2019, a deliverer ran over a stroller and fled. ${ }^{4}$ CCTV cameras fully recorded the whole delivery process of a food deliverer and found that in over $50 \mathrm{~min}$, the deliverer ran three red lights, twice drove in the wrong direction and once crossed the solid double yellow lines, violating traffic regulations six times. ${ }^{5}$ In terms of such violations, drivers have said that every deliverer is helpless experiencing a traffic violation. On one hand, they want to receive more orders, but on the other hand, it is more important to avoid punishment for being over the promised time. For example, if a deliverer for Meituan-takeout receives a bad review, he or she will be docked 50 yuan, and if he or she receives a complaint, he or she will be docked 500 yuan. ${ }^{6}$ Deliverers who exceed the time to deliver meals promised by the platform are more likely to receive poor reviews and complaints. The problem has been hotly debated, since it was first revealed, and concerns have been raised about the time constraints that data algorithms impose on delivery workers. In an effort to improve public opinion, ele.me announced on September 9,2020 , that it would add a button for "I'd like to wait five minutes or ten minutes" to its checkout function. ${ }^{7}$ However, the move set off a new uproar. Many netizens do not approve of ele.me, which they believe is a way for companies to persuade consumers to pay for their bad management. Many netizens believe ${ }^{8}$ that the extra 5-10 min will not solve the real problem, because such deliveries are not a "one-to-one" service. On the customer side, other orders are still sent, and it is likely that some deliverers will use the additional $5 \mathrm{~min}$ to accept more orders to make more money. The original intention was that the deliverers could slow down on the road, but the actual effect could be otherwise. Until the core problem is solved, the occupation of the takeaway driver (deliverer) is always high risk. Therefore, it is extremely urgent to research how platform enterprises make decision and carry out supply chain coordination to solve this kind of question.

Only entrepreneurs who give back to society in good faith and fulfill their social responsibilities can be recognized by society and meet the requirements of the times. ISO 26000 defines [30] social responsibility as an organization's responsibility for its decisions and activities that have an impact on society and the environment. The following transparent and ethical actions can be taken: (1) promoting sustainable development, including the health and well-being of society;

\footnotetext{
${ }^{4}$ See also: https://www.iqiyi.com/v_19rstvxen0.html.

5 See also: https://v.qq.com/iframe/preview.html?width=500\& height $=375 \&$ auto $=0 \& v i d=i 3152 \mathrm{n} 68 \mathrm{k} 3 \mathrm{~s}$.

6 See also: http://www.mnw.cn/news/cj/2319031.html.

7 See also: https://www.sohu.com/a/417220243_120640988.

${ }^{8}$ See also: https://baijiahao.baidu.com/s?id=167743723048128 $4290 \& w f r=$ spider $\&$ for $=$ pc.

(2) taking into account the expectations of stakeholders; (3) complying with relevant laws and international norms of conduct; and (4) integrating responsibility into the organization and the organizational relationship. In today's society, an enterprise that considers only short-term economic profit is obviously not aligned with the development of the times, as fulfilling social responsibility is the most effective way for enterprises to pursue long-term sustainable development. The improved social reputation associated with corporate social responsibility (CSR) will greatly improve long-term profits, and the loss of social reputation associated with a lack of CSR may bring greater economic losses to a corporation, even driving some businesses into trouble.

The effectiveness of the supply chain is directly related to the effective utilization of transportation. Each company uses different modes of transportation and routes to maximize profits. The distribution department uses transportation to reduce the actual cost of goods and thus to ensure reasonable consumer accessibility. Therefore, optimal supply chain decision-making and coordination become particularly important. From the perspective of the rational economic man hypothesis, in the supply chain system of sharing platform enterprises, platform enterprises and deliverers are rational economic men who seek to maximize economic returns. When the platform promises to provide consumers with a level of service (order delivery time) that exceeds the normal level of the deliverer's effort, the deliverer will try every means, such as traffic violations and other undesirable behaviour, to improve his or her service ability to avoid receiving complaints or punishment for being over the promised time. However, the bad behaviour of the deliverer in the order service process will affect the public cognition of the enterprise image and even cause consumer criticism of corporate social responsibility. How does a sharing platform company balance short-term economic gain with long-term social reputation, and how can effective incentives guide deliverers to pursue high returns without damaging the social reputation of the company? To answer these questions, this study will introduce the perspective of social responsibility to explore the optimal decision-making and coordination strategies of supply chain in different contract situations.

Based on the revenue-sharing contract, this study analyzes and discusses the optimal decisions of platform and deliverer separately in two situations: one that consider only economic benefits and another that combines economic and social benefits. The findings indicate that the response function of pricing to service level is the same between the two scenarios; that is, the platform will adopt the same pricing under the same commitment service level. When CSR and economic benefits' maximization are considered, the service-level commitment on the platform is related to the efforts of deliverers and the elasticity of demand/service, and 
under the optimal coordination situation of the supply chain with the goal of economic benefit maximization, the revenue sharing of deliverers is not enough to reduce their willingness to pursue high economic returns in violation of traffic rules. Through adding a contingency reward factor to the revenue-sharing contract with the goal of maximizing the comprehensive benefits, including social benefits, the platform can manage the behaviours of deliverers. The contribution is the reconstruction of the sharing revenue contract by combining economic and social benefits in the contract mechanism from the perspective of CSR and designing a contingency factor to resolve the practical dilemma, which has theoretical and practical innovation benefits in the supply chain of sharing economy.

\section{Literature review}

In this section, we consider papers on both optimal coordination of the supply chain and CSR topics that are most relevant to our study. We review previous works that have a direct connection with our study and have a major impact on identifying the current research gap.

\section{Supply chain coordination}

The research on supply chain coordination is divided into the following main aspects: contract design; optimal decision-making, including pricing, inventory, service level, and cost-control [1,11, 13, 16]; and comparisons of different decision constructs, such as decentralized and centralized decision-making [13, 16, 17]. Research questions focus on profit maximization. The areas, fields, or industries that are the subjects of research mainly include manufacturing, retail, service, science and technology, and other new areas. For example, analyses of the optimal decision-making and coordination of supply chain in China are based mostly on industry, such as knowledge [3], service [4], e-commerce [12, 22], outsourcing [18], logistics [7, 31], anchors [43], manufacturing [25], and retail [34].

From the perspective of methodology, most current researchers use principal-agent theory and game theory methods for analysis. In the application of principal-agent theory, some scholars have evolved the theory [3, 25, 43], and some have reformed the theoretical model. For example, four principal-agent models [34], three homogeneous double-agent models of neutrality, competition and cooperation [38], and a trust incentive model [8] have been proposed. Some scholars combine principal-agent theory with other theories, such as field theory, the tool variable method, and the principal-agent model. Among them, Dong et al. [3] studied the relationship between incentives and customers' non-spontaneous knowledge sharing behaviour and found that when enterprises cannot directly observe the level of customers' knowledge sharing efforts; that is, when there is an uncertain relationship between the level of customers' knowledge sharing and knowledge-based economic returns, simply providing a fixed reward to the customer is not an effective incentive that can maximize net returns in the knowledge economy. The optimal incentive must include the variable incentive component, which changes with the change in the return from the knowledge economy. Zhang et al. [38] found that competition and cooperation are superior to neutrality by analyzing the relationship between the optimal solution and the parameters of three homogeneous double-agent models: neutrality, competition, and cooperation. The principal maximum benefit of competition and cooperation will change with changes in incentive. A study on trust incentives for information sharing between service integrators and service providers by $\mathrm{He}$ et al. [8] found that under the information asymmetry condition, the level of effort, the coefficient of service ability, interaction, information sharing, and trust incentives are positively correlated. Pagell and $\mathrm{Wu}[29]$ suggested that the practices that lead to a more sustainable supply chain are equal parts best practices in traditional supply chain management and new behaviours, some of which run counter to existing accepted "best" practices. Carter and Easton [2] pointed out that the field of sustainable supply chain management (SSCM) has evolved from a perspective of standalone research in social and environmental areas through a corporate social responsibility perspective to the beginnings of the convergence of perspectives of sustainability as the triple bottom line and the emergence of SSCM as a theoretical framework.

The application of game theory includes theoretical evolution [18], variants [12], and combinations with other theories [41]. For example, Li et al. [18] studied the decision optimization of the supply chain when the manufacturer and the supplier undertake CSR and found that in the two outsourcing modes, regardless of which party undertakes CSR, both benefit from improving social welfare and increasing the overall profit of OEM enterprises and systems. Utilizing differential game theory, Zhang et al. [39] formulated the optimal decisions of the manufacturer and the retailer in two different game scenarios: a Stackelberg game and a cooperative game. Additionally, they proposed a new mechanism to coordinate the supply chain in which the manufacturer and the retailer share each other's advertising costs. Utilizing the Nash bargaining model, a cooperative game model was developed to implement profit sharing between the manufacturer and the retailer to achieve cooperation between them [20]. In addition to the principal-agent model and the game theory model, some scholars have used other methods, such as empirical tests [21] and experimental tests [27], to study optimal supply chain decision-making and coordination. In addition, some scholars have studied this problem from 
different perspectives, such as the hierarchy principle of the system [7], demand elasticity [22], the optimal combination of multiple objectives [5], and the dynamic perspective [31].

\section{Corporate social responsibility}

Earlier research on supply chain coordination focused mainly on contract coordination from the perspective of economic returns or profit maximization [20], and in recent years, as consumers have become more sensitive to corporate social responsibility $[23,24]$, there has been increasing research on sustainable supply chains and supply chain coordination with comprehensive consideration of economic benefits and environmental protection [6, 9, 33, 42].

Corporate social responsibility (CSR) has a significant impact on the operation of supply chains, and research has found that the manufacturer's CSR level and the manufacturer's and retailer's profits both increase with the proportion of CSR-sensitive consumers [24]. Johari and Hosseini-Motlagh [13] found that in a competitive environment, the proposed CSR cost-sharing contract increases market demand by significantly decreasing selling prices and increasing the level of CSR efforts. The research of Wang et al. [35] considered competition regarding CSR investment level to be an important component of firms' competitiveness with the emergence of consumers' awareness of CSR and found that the manufacturer's profit is convex with respect to consumers' environmental awareness [40]. A socially concerned manufacturer can offer a higher price for its products [14].

In addition, there are different CSR impacts on the operation and coordination of supply chains under different competitive environments and decision-making structures. For example, in different channel structures, exclusive vs. competitive retailing, there are different CSR impacts. Niu et al. [28] found that an overseas vaccine supplier will prefer competitive retailing when the overseas vaccine and the local vaccine are highly substitutable regardless of its objective of profit seeking or social responsibility seeking. Similarly, the supply chain will have different social responsibility strategies in monopoly and duopoly scenarios. Shi et al.'s research [32] revealed that the supply chain is more likely to be irresponsible and reduce the total CSR effort level in the duopoly scenario when conditions for each firm's optimal CSR efforts, strategy preferences, and CSR implications in monopoly and duopoly scenarios are considered. Then, with the impact of CSR, social welfare under a centralized decision-making scenario is always higher than that under a decentralized decision-making scenario [16]. The study of $\mathrm{Li}$ et al. [16] concluded that a multiple win for social welfare, consumers, and supply chain members can be achieved through a coordination contract to encourage the manufacturer to take corporate social responsibility seriously. However, when the CSR coefficient is above a certain threshold, the conflict among supply chain members becomes irreconcilable. Therefore, the impact of social responsibility on supply chain operation is a complex issue.

The complexity of the impact of social responsibility on supply chain coordination has been a concern of the academic community. Based on game theory, scholars have discussed the influence of negative social responsibility on the design of supply chain coordination contracts and found that the cost-sharing contract can improve the profit of both partners in a retailer-led supply chain. In a manufacturerled relationship, a profit-sharing contract can lead to better overall returns [26]. From the perspective of the global supply chain, Tian et al. [33] found that increasing the level of social responsibility of Chinese suppliers can increase the production demand and the economic benefits of stakeholders, but the economic returns of suppliers will decrease the demand for products, and the profits of stakeholders will increase with the improvement of the green level of products. However, the economic profit of Chinese suppliers is influenced by the level of social responsibility and the benefit of green production. Liu et al. [17] proposed that at present, there is a serious lack of cooperation in promoting the social responsibility of multinational enterprises. They designed a punishment model, discussed the optimal decision-making of supply chain members under centralized and decentralized decision-making mechanisms, and then analyzed the influence of the penalty rate on the input of social responsibility.

\section{Research gap}

Technological innovation has promoted the innovation of business models, and the emergence of new business forms and new models has presented new opportunities and challenges to supply chain coordination. Moreover, the expansion of public events and online public opinion, such as public health events or network hot events, has made the coordination of the supply chain increasingly vulnerable. Supply chain coordination needs to break out of traditional approaches and focus on issues in new technology areas as well as new issues created by new technology applications. For example, in the sharing economy, platforms and deliverers face dilemmas such as the one mentioned in the introduction of this paper.

There is also a principal-agent relationship between the sharing economy platform and the service deliverer (rider). The conclusion of the above study using the principal-agent model has important reference significance for this study. In particular, the conclusion on the variable incentive scheme [3] provides a theoretical basis for this study to add variable incentive factors to the revenue-sharing contract mechanism. In addition, in the literature on supply chain coordination using game theory, the assumption of corporate social 
Table 1 Comparison of the most relevant studies with this paper

\begin{tabular}{|c|c|c|c|}
\hline \multirow[t]{2}{*}{ Areas } & \multicolumn{2}{|l|}{ Relevant studies } & \multirow{2}{*}{$\begin{array}{l}\text { This study } \\
\text { Sharing economy }\end{array}$} \\
\hline & Traditional industries and fields & Most relevant studies & \\
\hline Players and relationship & Between organizations & Li et al. [18], Carter and Easton [2] & Organizations and individuals \\
\hline Objective & $\begin{array}{l}\text { Profit maximization of supply chain } \\
\text { members; social welfare }\end{array}$ & $\begin{array}{l}\text { Bharadwaj et al. [1], Li et al. [16], } \\
\text { Johari and Hosseini-Motlagh } \\
\text { [13], Ishfaq and Raja [11] }\end{array}$ & $\begin{array}{l}\text { Balance between short-term economic } \\
\text { returns and long-term comprehensive } \\
\text { benefits of platform }\end{array}$ \\
\hline Research perspective & Environment & $\begin{array}{l}\text { Hosseini-Motlagh et al. [9], } \\
\text { Heydari and Rafiei [6], Zhang } \\
\text { et al. [42], Tian et al. [33], Zhang } \\
\text { et al. [40] }\end{array}$ & Co-operator's behaviour \\
\hline Implicit hypothetical logic & $\begin{array}{l}\text { Conflict view: Increasing social } \\
\text { responsibility input will increase } \\
\text { costs and reduce profits }\end{array}$ & $\begin{array}{l}\text { Tian et al. [33], Shi et al. [32], } \\
\text { Mahdiraji et al. [26] }\end{array}$ & $\begin{array}{l}\text { Symbiotic and balanced: increas- } \\
\text { ing social responsibility level will } \\
\text { improve social reputation and then } \\
\text { increase long-term returns for supply } \\
\text { chain }\end{array}$ \\
\hline
\end{tabular}

responsibility is beneficial to the improvement of social welfare and profit, and the research literature on the sharing value corporate social responsibility paradigm [36] suggests that corporate and social relations should be positioned to provide symbiotic co-benefits. These studies provide a theoretical basis and foundation for our study.

At present, the research on CSR and the sharing economy is more qualitative research and content research [4] than quantitative research on actual enterprises. Naik and Satapathy [27] pointed out that the SGO algorithm with social factors has shown better performance in solving problems than other algorithms, which shows that research on optimal decision-making and coordination of supply chains under the perspective of social responsibility is of great significance. A large-scale survey with 420 participants showed that investment recovery (IR) practices and corporate social responsibility (CSR) conducted by sharing economy platforms significantly and positively affected customers' intention to use sharing economy-based services/products [10]. However, in the existing literature, regardless of whether the principal-agent model or game theory is used to study optimal supply chain decision-making and coordination, most studies have discussed optimization problems with the goal of maximizing economic returns. There are few studies on this subject from the perspective of social responsibility, especially on the basis of the "social responsibility $\rightarrow$ social reputation $\rightarrow$ long-term benefit" logic, which transforms social responsibility into comprehensive benefit. There are few research results in the field of supply chain optimal coordination. Therefore, this study assumes a logic of "increasing the social responsibility level will improve social reputation and then increase the long-term returns for enterprises" and then transforms social responsibility into a comprehensive benefit and brings it into the optimal supply chain coordination research to explore how to achieve optimal supply chain decision-making and coordination in the context of the sharing economy.

Through the literature review, we identified some differences between this study and the most relevant previous studies (Table 1). The traditional research on supply chain coordination focuses mainly on cooperation and contract relationships between upstream and downstream organizations of the supply chain, and in the field of the sharing economy, platform companies and delivery riders or drivers are a loose supply chain partnership of organizations and individuals. As a service provider, the rider becomes an indispensable subject in the supply chain, which is an important link for direct contact with the end customer. In the supply chain dominated by the sharing economy platform, coordination between the platform organization and the individual service providers is of great practical significance. There have been few studies on the impact of the service deliverers' behaviours as a co-operator on the fulfillment of the social responsibility and social reputation of the platform enterprises and then on the long-term profit of the supply chain. However, this issue has become a hot social topic in relation to the development of the sharing economy. With the increasing sensitivity to user social responsibility, this issue will become increasingly prominent and needs to be discussed in depth.

In addition, in the field of supply chain coordination, more attention is paid to the maximization of economic returns than to the benefits of enterprises on the basis of social responsibility input. Even in supply chain optimization and coordination, the problem of social responsibility is discussed mostly from the perspective of the environment, and a sustainable supply chain is constructed by the balance between an enterprise's economic goals and environmental protection or other social welfare. Based on this perspective, for enterprises, increasing the level of social responsibility 
is an output. Here, there is an implicit hypothetical logic based on the conflict view that increasing social responsibility input will increase costs and reduce profits. However, we found new evidence in a previous study [36] that a new CSR paradigm has balanced comprehensive value. The research reveals a new logic that establishes links between social problems and social needs and business opportunities $\rightarrow$ solving social problems and social needs embedded in the core business unit of the enterprise $\rightarrow$ increasing the total economic value and social value $\rightarrow$ enhancing the competitiveness of the enterprise and simultaneously achieving social progress $\rightarrow$ creating shared value. Furthermore, other studies show that improving the social responsibility consciousness of consumers and raising enterprises' CSR level can achieve a win-win situation for revenues and social welfare [24]. These research conclusions provide much inspiration. Therefore, we set up the implicit logic of this study as follows: increasing the social responsibility level will improve social reputation and then increase the longterm returns for the supply chain. This is a symbiotic and balanced view.

\section{Method}

Based on the revenue-sharing contract, this study built the basic model as follows to define the demand function decided by the price of service and service level, and the objective function of the supply chain separately from revenue maximization and comprehensive benefit maximization.

\section{Basic model}

Suppose that the total market volume is one hundred per cent, expressed in unit 1, the demand is a decreasing function of price and an increasing function of service level, the demand function [22] is:

$D=1-P+r S$,

where $D$ is the market demand; $P$ is the order price; $S$ is the promised service level, which is the order delivery time promised by the platform to customers, such as the delivery time of takeaway orders; and $0<r$ is the elasticity of demand to service level or the sensitivity coefficient of demand to service level.

Suppose the objective function of the supply chain from an economic benefit perspective is:

$R=(P-c) D-C(S)$.

In the above function, $c \geq 0$ is the unit variable cost, which means the variable cost allocated to each order, including the cost paid by the platform to upstream enterprises, such as the order price paid to restaurants, and other variable cost paid to get an order; $C(S)$ represents the service cost to improve the level of service. The economic benefit $(R)$ is determined by the price and cost. Then, $U$ is used to express the social benefit under the influence of social reputation; and $\pi$ is used to express long-term comprehensive benefit including short-term economic benefit and social benefit $(U)$ under the influence of social reputation. Assuming $\tau$ is an arbitrary constant, $e$ is used to represent the service efforts of the deliverer; the social benefit $(U)$ is the function of the deliverer's efforts $(e)$ :

$U(e)=a e^{2}+b e+\tau, \quad a<0, b>0$.

And the revenue function of supply chain from a comprehensive benefit perspective is:

$\pi=(P-c) D-C(S)+U$.

Suppose that $C(x)$ can be expressed as $[19,22,37]$ :

$C(x)=\frac{k x^{2}}{2}$.

It is strictly increasing quadratic function, and $k>0$ is the service cost coefficient, $k_{1}>0$ for the platform, and $k_{2}>0$ for the deliverer, with $k=k_{1}+k_{2}$; furthermore, the relationship between service level $(S)$ and efforts $(e)$ is:

$S=\theta e+\varepsilon$.

In the above function, $\theta$ is the marginal coefficient of service level to effort, which can be understood as a constant and $\varepsilon$ is an arbitrary constant. In this research, the service level is mainly measured by service delivery time. The derivation and proof of the above formula (6) is shown in appendix. The service level $(S)$ promised by the platform is calculated by the algorithm based on the average delivery time. The harder the deliverer works, the shorter the average delivery time, and the higher the service level of the platform.

Based on the above basic model, the optimal coordination mechanism of the supply chain with the sharing economy platform as the core under two scenarios is discussed: maximizing short-term economic returns or considering the impact of social reputation on the long-term comprehensive benefits. In two different situations, the optimal decisionmaking behaviours of different decision-makers under decentralized decision-making and centralized decisionmaking are compared, and the coordination strategies that platforms effectively manage the deliverer's behaviours are found.

In the supply chain of sharing economy, platform operators are decision-makers of service price. Then, the commitment service level is dynamically calculated by the platform algorithm based on the historical data of service delivery 
time; that is, this algorithm determines the commitment service level by the average delivery time. In the decentralized decision structure, the decision order is divided into two stages:

The first stage: before signing the contract, the sequence of events is:

(1) the platform operators determine revenue-sharing proportion $(\emptyset)$;

(2) the deliverers decide whether to accept the contract and establish a loose cooperative relationship based on this contract;

The second stage: after signing the contract, the sequence of events is:

(1) the platform operators determine the service pricing $(P)$. And the commitment service level $(S)$ is dynamically estimated according to the system algorithm based on average delivery time;

(2) the deliverers chooses the appropriate level of effort $(e)$ to fulfill specific orders after observing pricing and commitment service levels from platform.

The research focus on how the platform operators to coordinate the behaviours of deliverers after signing revenuesharing contract; therefore, this paper mainly discusses the decision-making events in the second stage and the main decision variables include price $(P)$ and effort level $(e)$. Among them, the former is determined by platform operators, and the latter is decided by the deliverers.

\section{Scenario one: optimal decision-making from the perspective of maximizing short-term economic returns}

Under the premise of considering only the economic benefits, the sharing platform signs a revenue-sharing contract with the takeaway drivers (deliverers) to improve the overall revenue. Based on the revenue-sharing contract coordination mechanism, this paper analyzes the optimal pricing decision-making of platform enterprises and dynamic estimation of commitment service level, and the optimal service effort of deliverers. According to the objective function of economic benefit in the basic model, the objective function of the platform can be written as follows:

$R_{1}=((1-\emptyset) P-c) D-C_{1}(S)$,

where $0<\emptyset<1$ is the proportion of revenue sharing between the platform and the deliverer; and $C_{1}(S)$ is the cost paid by the platform to achieve the promised service level.

The revenue function of the deliverer is expressed as:
$R_{2}=\emptyset P \times D-C_{2}(S)$.

In the above function, $C_{2}(S)$ is the effort cost paid by the deliverer to meet the service level promised by the platform. Therefore:

$C_{1}(S)+C_{2}(S)=C(S)$.

\section{Centralized decision-making to maximize the overall revenue of the supply chain}

Based on functions (1), (2), and (5):

$R=(P-c) D-C(S)=(P-c)(1-P+r S)-\frac{k S^{2}}{2}$.

The first and second derivatives of $P$ and $S$ are calculated, where the second derivatives are all less than zero (functions $11,12)$, which means that $R$ is a concave function and has a maximum value:

$\frac{\partial R}{\partial P}=1-2 P+c+r S, \quad \frac{\partial^{2} R}{\partial P^{2}}=-2<0$

$\frac{\partial R}{\partial e}=\theta r(P-c)-k \theta^{2} e-k \theta \varepsilon, \quad \frac{\partial^{2} R}{\partial e^{2}}=-k \theta^{2}<0$.

Therefore, making the first derivatives of $P$ and $S$ equal to zero, the optimal price and the optimal service-level commitment under the maximization of overall revenue are determined as follows:

$P_{\max (R)}^{*}=\frac{1+r S+c}{2}$

$e_{\max (R)}^{*}=\frac{r(P-c)}{k \theta}-\frac{\varepsilon}{\theta}$.

Under the optimal price, put $P_{\max (R)}^{*}$ in the expression of $e_{\max (R)}^{*}$ to obtain:

$e_{\max (R)}^{*}=\frac{r(1-c)+\left(r^{2}-2 k\right) \varepsilon}{\left(2 k-r^{2}\right) \theta}$.

If and only if $0<r<\sqrt{2 k}$, formula (15) is meaningful. Because there is such a relationship between the commitment service level and the deliverer's efforts, i.e., $S=\theta e+\varepsilon$, when $\varepsilon=0$ and $\theta=1$, the marginal improvement of service level is equal to the deliverer's marginal effort. Then, under the scenario of overall revenue maximization, the expected efforts of deliverers on the platform are the optimal service level $\frac{r(1-c)}{2 k-r^{2}}$, which is related to the elasticity of demand to service $(r)$ and cost coefficient $(k)$. Thus, theorem one can be obtained: 
Theorem 1 Under the centralized decision-making scenario, the optimal efforts and service level to maximize the overall economic revenue of the supply chain are related to the elasticity of demand to service $(r)$ and cost coefficient $(k)$, that is, $\frac{r(1-c)}{2 k-r^{2}}(\varepsilon=0$ and $\theta=1,0<r<\sqrt{2 k})$.

\section{Decentralized decision-making: deliverers and platforms pursue their own economic returns maximization}

Similar to the $R$ function, $R_{1}$ and $R_{2}$ function takes concave forms. The optimal pricing and efforts of deliverers under the revenue maximization of the supply chain are as follows:

$$
\begin{aligned}
& P_{\max \left(R_{1}\right)}^{*}=\frac{(1+r S)(1-\emptyset)+c}{2(1-\emptyset)} \\
& e_{\max \left(R_{1}\right)}^{*}=\frac{r((1-\emptyset) p-c)}{k_{1} \theta}-\frac{\varepsilon}{\theta} .
\end{aligned}
$$

Put $P_{\max \left(R_{1}\right)}^{*}$ in the expression of $e_{\max \left(R_{1}\right)}^{*}$ to obtain:

$e_{\max \left(R_{1}\right)}^{*}=\frac{r(1-\emptyset-c)+\left(r^{2}-2 k_{1}\right) \varepsilon}{\left[2 k_{1}-r^{2}(1-\emptyset)\right] \theta}$.

The premise of formula (18) is:

$$
\left\{\begin{array}{c}
\emptyset>\left(1-\frac{2 k_{1}}{r^{2}}\right)>0 \\
1-\emptyset>c
\end{array} .\right.
$$

When $\varepsilon=0$ and $\theta=1$ :

$$
e_{\max \left(R_{1}\right)}^{*}=\frac{r(1-\emptyset-c)}{2 k_{1}-r^{2}(1-\emptyset)} .
$$

Thus the commitment service level is $\frac{r(1-\emptyset-c)}{2 k_{1}-r^{2}(1-\emptyset)}$ based on the formula (20) from the perspective of platform's revenue maximization. In the case of $1-\emptyset<c$, for the platform operators, their marginal revenue is not enough to cover the marginal costs. Platform operators will lose money if they receive a lower share of revenue than the unit variable cost of the order. To ensure the feasibility of operation, platform operators will set higher proportion of revenue sharing than the order variable cost before signing revenue-sharing contract, and thus, $1-\emptyset \geq c$ is the premise condition that platform operator and deliverer can establish cooperative relationship based on revenue-sharing contract.

The optimal pricing under the maximization of deliverers' revenue is:

$P_{\max \left(R_{2}\right)}^{*}=\frac{1+r S}{2}$.

Thus, $P_{\max \left(R_{1}\right)}^{*}>P_{\max \left(R_{2}\right)}^{*}$; the optimal level of effort is as follows: $e_{\max \left(R_{2}\right)}^{*}=\frac{\emptyset r}{\theta\left(2 k_{2}-\emptyset r^{2}\right)}-\frac{\varepsilon}{\theta}$.

When $\varepsilon=0$ and $\theta=1$, and thus:

$e_{\max \left(R_{2}\right)}^{*}=\frac{\emptyset r}{\left(2 k_{2}-\emptyset r^{2}\right)}$.

If and only if $2 k_{2}-\emptyset r^{2}>0$, the above formula is true; therefore:

$\emptyset<\frac{2 k_{2}}{r^{2}}<1$.

Based on the functions (18), (19), and (24), the following relationships exist:

$\left\{\begin{array}{c}\left(1-\frac{2 k_{1}}{r^{2}}\right)<\emptyset<\frac{2 k_{2}}{r^{2}} \\ 1-\emptyset \geq c \\ \sqrt{2 k_{2}}<r<\sqrt{2 k_{1}}\end{array}\right.$.

Theorem 2 In the case of $\varepsilon=0 ; \theta=1$, under the decentralized decision-making scenario, the commitment service level and the optimal effort of deliverers to maximize the economic benefits of the platform enterprise are $\frac{r(1-\emptyset-c)}{2 k_{1}-r^{2}(1-\emptyset)}$. The optimal effort level decided by deliverers is $\frac{\emptyset r}{\left(2 k_{2}-\emptyset r^{2}\right)}$ from their own benefits maximization perspective. Here, $\left(1-\frac{2 k_{1}}{r^{2}}\right)<\emptyset<\frac{2 k_{2}}{r^{2}}, 1-\emptyset \geq c$, and $\sqrt{2 k_{2}}<r<\sqrt{2 k_{1}}$.

Platform operators in the industry, such as Meituan system, often estimate the commitment service level based on the average delivery time which is affected by the effort of deliverers. In the case of $\varepsilon=0$ and $\theta=1$, exists $S_{\max \left(R_{2}\right)}^{*}=e_{\max \left(R_{2}\right)}^{*}$ and $S_{\max \left(R_{1}\right)}^{*}=e_{\max \left(R_{1}\right)}^{*}$

The commitment service level in the platform is related to the elasticity of demand to service $(r) /$ the revenue-sharing proportion $(\emptyset)$ and cost coefficient $\left(k_{1}\right)$ of the platform, and the optimal decision about service effort level from deliverers is related to the elasticity of demand to service $(r) /$ the revenue-sharing proportion $(\emptyset)$ and cost coefficient $\left(k_{2}\right)$ paid by the deliverers.

The revenue-sharing proportion paid by the platform to the deliverer is less than the ratio between twice the deliverer's cost coefficient and the square of elasticity of demand/ service (formula 24). Under the given revenue-sharing proportion, the higher the elasticity of demand/service $(r)$, the more willing the deliverer is to choose the higher service efforts; that is, the more sensitive the user is to the delivery time, the greater efforts the deliverer will make to improve the delivery time. 


\section{Scenario two: optimal decision-making considering the impact of social reputation on the long-term comprehensive benefit of platform enterprises}

When enterprises begin to pay attention to the impact of social responsibility on their long-term development, the impact of social responsibility on corporate social reputation will be considered. In reality, the social reputation associated with the fulfillment of social responsibility cannot be ignored. Therefore, the assumption is that enterprises pay more attention to the comprehensive benefits, including social benefits associated with social responsibility and social reputation in addition to economic benefits. Considering the influence of social reputation on long-term comprehensive revenue, under the revenue-sharing contract mechanism, it is necessary to explore how platform enterprises can encourage and manage deliverers to maximize their own profits without damaging the social reputation of the platform.

While pursuing business goals, platform enterprises also need to undertake social responsibility. When hot event causes a positive impact on corporate social responsibility, it will bring a good social reputation to an enterprise and increase long-term revenue; on the contrary, if an event involving social responsibility is negative, it will cause the enterprise to lose social reputation and long-term benefit. The various behaviours of deliverers in the process of delivering meals represent the image of the platform enterprises. For example, takeout riders who rush through red lights or frequent traffic violations to deliver orders on time will have some negative effects. If deliverers perform good works, such as saving people, in the process of delivering meals or other goods, it will enhance the social reputation of the platform enterprise. Under the constraint of the given service level $(S)$, deliverers will choose the corresponding efforts to maximize their own benefits. The greater the effort the deliverer must make, the shorter the average delivery time is, and the higher the service level the platform promises to consumers. However, when the efforts of deliverers reach or exceed the normal level, the improvement of service level may lead to problems such as traffic violations. Therefore, this study assumes that the long-term benefits or social benefits associated with the increase and loss of the social reputation of the platform are a function of deliverers' efforts, and the function is an inverted U-shaped curve. The expression is as follows:

$U(e)=a e^{2}+b e+\tau$.

In the formula, $a<0$ and $b>0$ are constant. It is an inverse U-type function and provides a maximum.

When formula (26) holds, the social benefits of the platform are the greatest: $e_{0}=-\frac{b}{2 a}$

When the deliverer's effort exceeds $e_{0}$, the social benefits begin to decline, and the platform may face the loss of social reputation caused by the illegal behaviour of deliverers.

\section{Centralized decision-making to maximize the overall long-term comprehensive benefits of the supply chain}

Based on function (4):

$$
\begin{aligned}
\pi & =(P-c) D-C(S)+U(e) \\
& =(P-c)(1-P+r S)-k \frac{S^{2}}{2}+a e^{2}+b e+\tau \\
& =(P-c)(1-P+r \theta e+r \varepsilon)-\frac{k}{2}(\theta e+\varepsilon)^{2}+a e^{2}+b e+\tau .
\end{aligned}
$$

The second derivative of the above function to $P, S$, and $e$ is less than zero. It is a concave function and has a maximum.

The optimal price under the maximization of $\pi$ is:

$P_{\max (\pi)}^{*}=\frac{1+r S+c}{2}$.

The optimal effort of deliverers is as follows from the perspective of maximizing the overall benefits of the supply chain:

$e_{\max (\pi)}^{*}=\frac{b+[P-c] r \theta-k \theta \varepsilon}{\theta^{2} k-2 a}$.

Put $P_{\max (\pi)}^{*}$ into $e_{\max (\pi)}^{*}$ to obtain:

$e_{\max (\pi)}^{*}=\frac{2 b+[1-c] r \theta-2 k \theta \varepsilon+r^{2} \theta \varepsilon}{2 \theta^{2} k-4 a-\theta^{2} r^{2}}$.

According to the formula (6):

$S_{\max (\pi)}^{*}=\frac{2 b \theta+r(1-c) \theta^{2}-4 a \varepsilon}{2 k \theta^{2}-4 a-\theta^{2} r^{2}}$.

When $\varepsilon=0$ and $\theta=1$, we get:

$e_{\max (\pi)}^{*}=\frac{2 b+r(1-c)}{2 k-4 a-r^{2}}$.

Theorem 3 Under the centralized decision-making scenario, the service level committed by the platform can be expressed as $\frac{2 b \theta+r(1-c) \theta^{2}-4 a \varepsilon}{2 k \theta^{2}-4 a-\theta^{2} r^{2}}$. When $\varepsilon=0$ and $\theta=1$, the commitment service level and the optimal efforts of deliverers are $\frac{2 b+r(1-c)}{2 k-4 a-r^{2}}$ from the perspective of overall revenue maximization. 
Decentralized decision-making: platforms pursue long-term comprehensive benefit maximization, and deliverers' objective is maximizing economic returns

The comprehensive benefit of the platform can be expressed as:

$$
\begin{aligned}
\pi_{1} & =((1-\emptyset) P-c) D-C_{1}(S)+U(e)-\beta(e) \\
& =((1-\emptyset) P-c)(1-P+r S)-k_{1} \frac{S^{2}}{2}+a e^{2}+b e+\tau-\delta e \\
& =((1-\emptyset) P-c)(1-P+r \theta e+r \varepsilon)-\frac{k_{1}}{2}(\theta e+\varepsilon)^{2}+a e^{2}+b e+\tau-\delta e .
\end{aligned}
$$

In the formula, $\beta$ is the reward factor, which represents the reward paid by the platform to the deliverer or the punishment imposed on the deliverer, and $\beta=\delta e$ is the contingent reward factor based on the efforts of deliverers; when $e>e_{0},-1<\delta<0$, then $\beta<0$ and $\delta$ is the penalty coefficient. In the case of $e<e_{0}, 0<\delta \leq 1$, then, $\beta>0$ and $\delta$ is the reward coefficient.

Under the scenario of comprehensive benefit maximization, the optimal pricing, the optimal service level committed by the platform, and the level of efforts, the platform expects deliverers to make are as follows:

$$
\begin{aligned}
& P_{\max \left(\pi_{1}\right)}^{*}=\frac{(1-\emptyset)(1+r \theta e+r \varepsilon)+c}{2(1-\emptyset)}=\frac{(1-\emptyset)(1+r S)+c}{2(1-\emptyset)} \\
& e_{\max \left(\pi_{1}\right)}^{*}=\frac{b+[(1-\emptyset) P-c] r \theta-\varepsilon \theta k_{1}-\delta}{\theta^{2} k_{1}-2 a} .
\end{aligned}
$$

The above formulas (34) and (16) show that when considering the influence of social reputation on the long-term comprehensive benefits of the platform, the response function of the optimal pricing to the commitment service level is the same. Under the given service level (in other words, the platform promises the same service level), the optimal pricing adopted by the platform enterprise in pursuit of its own comprehensive benefit maximization is no different from that under the condition of considering only the maximization of short-term economic revenue.

$$
\begin{aligned}
& \text { Put } P_{\max \left(\pi_{1}\right)}^{*} \text { into } e_{\max \left(\pi_{1}\right)}^{*} \text {, then: } \\
& e_{\max \left(\pi_{1}\right)}^{*}=\frac{2(b-\delta)+(1-\emptyset-c) r \theta+r^{2} \theta \varepsilon-2 \varepsilon \theta k_{1}}{2 \theta^{2} k_{1}-4 a-(1-\emptyset) r^{2} \theta^{2}} .
\end{aligned}
$$

Thus:

$$
S_{\max \left(\pi_{1}\right)}^{*}=\frac{2(b-\delta) \theta+(1-\emptyset-c) r \theta^{2}-4 a \varepsilon}{2 \theta^{2} k_{1}-4 a-(1-\emptyset) r^{2} \theta^{2}} .
$$

The optimal efforts of deliverers based on the above optimal price (function 34) can be expressed as the function of
(36), and the service level committed by the platform reach the level described in formula (37).

When $\varepsilon=0$ and $\theta=1$ :

$$
e_{\max \left(\pi_{1}\right)}^{*}=S_{\max \left(\pi_{1}\right)}^{*}=\frac{2(b-\delta)+(1-\emptyset-c) r}{2 k_{1}-4 a-(1-\emptyset) r^{2}} .
$$

Based on functions (6) and (8), the deliverer's revenue function can be expressed as:

$R_{2}=\emptyset P \times D-C_{2}(S)=\emptyset P \times D-C_{2}(\theta e+\varepsilon)$.

To restrict deliverers to pursuing the maximum revenue without illegal behaviours, platform enterprises assign them additional rewards or punishments on the premise of maximizing the comprehensive benefits of the platform. Therefore, when the reward factor is increased, the revenue function of the deliverers is as follows:

$$
\begin{aligned}
\pi_{2} & =\emptyset P \times D-C_{2}(S)+\beta(e) \\
& =\emptyset P \times D-C_{2}(\theta e+\varepsilon)+\beta(e) .
\end{aligned}
$$

Without considering the reward factor, the optimal decision is as follows:

$e_{\max \left(R_{2}\right)}^{*}=\frac{\emptyset r}{\theta\left(2 k_{2}-\emptyset r^{2}\right)}-\frac{\varepsilon}{\theta}$.

Considering the reward factor, the optimal decision to maximize the deliverer's comprehensive benefit is as follows:

$e_{\max \left(\pi_{2}\right)}^{*}=\frac{\theta\left(\emptyset r P-k_{2} \varepsilon\right)+\delta}{k_{2} \theta^{2}}$.

Put $P_{\max \left(\pi_{1}\right)}^{*}$ into $e_{\max \left(\pi_{2}\right)}^{*}$, then:

$e_{\max \left(\pi_{2}\right)}^{*}=\frac{(1-\emptyset)\left[\theta \emptyset r(1+r \varepsilon)-2 k_{2} \varepsilon \theta+2 \delta\right]+c \theta \emptyset r}{\theta^{2}(1-\emptyset)\left(2 k_{2}-\emptyset r^{2}\right)}$.

When $\varepsilon=0$ and $\theta=1$ :

$e_{\max \left(\pi_{2}\right)}^{*}=\frac{(1-\emptyset) 2 \delta+(1-\emptyset+c) \emptyset r}{(1-\emptyset)\left(2 k_{2}-\emptyset r^{2}\right)}$.

Theorem 4 Under the decentralized decision-making scenario, the optimal effort of deliverers is $\frac{2(b-\delta)+(1-\emptyset-c) r \theta+r^{2} \theta \varepsilon-2 \varepsilon \theta k_{1}}{2 \theta^{2} k_{1}-4 a-(1-\emptyset) r^{2} \theta^{2}}$ to maximize the comprehensive benefit of the platform enterprise and the commitment service level is $\frac{2(b-\delta) \theta+(1-\emptyset-c) r \theta^{2}-4 a \varepsilon}{2 \theta^{2} k_{1}-4 a-(1-\emptyset) r^{2} \theta^{2}}$. However, the optimal effort that can help deliverers to maximize their comprehensive income is $\frac{(1-\varnothing)\left[\theta \emptyset r(1+r \varepsilon)-2 k_{2} \varepsilon \theta+2 \delta\right]+c \theta \emptyset r}{\theta^{2}(1-\emptyset)\left(2 k_{2}-\emptyset r^{2}\right)}$. When $\varepsilon=0$ and $\theta=1$, 
the service level to maximize the comprehensive benefit of the platform enterprise is $\frac{2(b-\delta)+(1-\emptyset-c) r}{2 k_{1}-4 a-(1-\emptyset) r^{2}}$, which is the same level of effort the platform expects from deliverers. However, the optimal effort that can help deliverers maximize their comprehensive income is $\frac{(1-\emptyset) 2 \delta+(1-\emptyset+c) \emptyset r}{(1-\emptyset)\left(2 k_{2}-\emptyset r^{2}\right)}$.

Based on the Theorems 2 and 4, in the case of $\varepsilon=0$ and $\theta=1$, when $\delta>-\frac{c \emptyset r}{2(1-\emptyset)}$, exists $e_{\max \left(\pi_{2}\right)}^{*}>e_{\max \left(R_{2}\right)}^{*}$. It reveals that the optimal effort of the deliverers considering the maximum of his own comprehensive benefit $\left(\pi_{2}\right)$ is higher than the optimal effort only considering the revenue sharing on orders $\left(R_{2}\right)$, and thus, platform operators can improve service level by rewarding $(\delta)$ deliverers to improve their efforts. When $\delta<-\frac{c \emptyset r}{2(1-\emptyset)}$, exists $e_{\max \left(\pi_{2}\right)}^{*}<e_{\max \left(R_{2}\right)}^{*}$. It means that the optimal effort of the deliverers considering the maximum of his own comprehensive benefit $\left(\pi_{2}\right)$ is less than the optimal effort only considering the revenue sharing on orders $\left(R_{2}\right)$. In this case, the incentive effect of reward factor $\delta$ disappeared; therefore, platform operators cannot improve service level by rewarding $(\delta)$ deliverers.

\section{Results and discussion}

In this section, the optimal decision-making of platform enterprises and service deliverers in different situations is compared and the optimal coordination of supply chain is discussed, including the platform's optimal pricing, and the deliverer's optimal effort, conditions for optimal coordination, and a reasonable range of reward factors.

\section{Optimal decision and coordination considering short-term economic returns maximization}

In the centralized decision-making situation, to maximize the overall revenue of the supply chain, the optimal pricing determined by the platform enterprises is $P_{\max (R)}^{*}=\frac{1+r S+c}{2}$. In the decentralized decision-making situation, the platform aims to maximize its revenue, and the optimal pricing is $P_{\max \left(R_{1}\right)}^{*}=\frac{(1+r S)(1-\varnothing)+c}{2(1-\varnothing)}$. When the optimal pricing of centralized decision-making and decentralized decision-making are compared, the results indicate that:

$\frac{1+r S+c}{2}-\frac{(1+r S)(1-\emptyset)+c}{2(1-\emptyset)}=\frac{-c \emptyset}{2(1-\emptyset)}<0$.

That is,

$P_{\max (R)}^{*}<P_{\max \left(R_{1}\right)}^{*}$.
This shows that when the platform enterprise has the goal of maximizing its revenue, the pricing will be higher than that under the scenario of maximizing the overall revenue of the supply chain, which is disadvantageous to consumers and is associated with the possibility of reducing social welfare. However, there is no pricing power for the deliverer, and the platform enterprise will not actively choose the optimal pricing under the scenario of maximizing the deliverer's economic benefit.

When $\varepsilon=0$ and $\theta=1$, in the centralized decision-making situation, the optimal effort of deliverer to maximize supply chain revenue is $e_{\max (R)}^{*}=\frac{r(1-c)}{2 k-r^{2}}$; and in the decentralized decision-making situation, the effort that platform operators expect deliverers to put into maximizing platform's revenue is $\frac{r(1-\varnothing)-r c}{2 k_{1}-r^{2}(1-\emptyset)}$; but the optimal effort for the deliverers to maximize their own profit is $\frac{\emptyset r}{2 k_{2}-\emptyset r^{2}}$. When the commitment service level and the optimal effort degree of decentralized decision-making are equal to the optimal level of centralized decision-making, the supply chain achieves the optimal coordination state. Therefore, suppose that:

$e_{\max \left(R_{2}\right)}^{*}=e_{\max \left(R_{1}\right)}^{*}=e_{\max (R)}^{*}$.

Then, we get:

$\left\{\begin{array}{l}\emptyset=\frac{2 k_{2}(1-c)}{2 k-r^{2} c} \\ r<\sqrt{\frac{2 k}{c}}\end{array}\right.$.

Based on the function (25) $1-\emptyset>c$, exists $\mathrm{c}<1$, and thus, $r<\sqrt{\frac{2 k}{c}}$. The results show that the optimal effort decision in decentralized decision-making is the same as in centralized decision-making, supply chain achieves optimal coordination, when the proportion of revenue sharing between the platform and deliverer is equal to $\frac{2 k_{2}(1-c)}{2 k-r^{2} c}(\varepsilon=0$ and $\theta=1)$. The commitment service level in the platform from the perspective of maximizing its own revenue is equal to the optimal level of supply chain revenue maximization. And the optimal effort to maximize the deliverer's revenue is equal to the level to maximize the overall revenue of supply chain and the revenue of platform. It can been seen from the function (47) that the key factors in determining whether the supply chain can achieve optimal coordination include the demand elasticity of consumers, variable cost of service order in the platform, and service cost coefficients.

Theorem 5 With the goal of economic returns maximization, when the proportion of revenue sharing between the platform and deliverer is equal to $\frac{2 k_{2}(1-c)}{2 k-r^{2} c}$ in the case of $\varepsilon=0$ and $\theta=1$, supply chain achieves optimal 
coordination, and in the optimal coordination state, the optimal effort of deliverers is $\frac{r(1-c)}{2 k-r^{2}}$.

The service level promised by the platform increases with the improvement of the average service level of the deliverers, this trend pushes the marginal effort cost of deliverers to increase. However, the proportion of revenue sharing is relatively stable for a period of time after the contract is signed. When the increase in unit cost caused by the improvement of service level is not fully covered by the revenue sharing from the platform, deliverers who aim to maximize their economic benefit are likely to take illegal actions to increase the number of orders. Of course, the deliverers do not consider the cost of life. Under the revenue-sharing contract based on the premise of maximizing economic benefits, the supply chain can achieve optimal coordination. To a certain extent, platform operators encourage deliverers to make corresponding efforts matching the platform's expected level through setting a reasonable share of revenue. However, it cannot solve the dilemma mentioned in the introduction of the social responsibility of platform enterprises being questionable due to deliverers' violations.

\section{Optimal decision and coordination considering social responsibility}

To solve the social responsibility dilemma faced by platform enterprises, in scenario 2, the study incorporates the social reputation promotion associated with the enterprise undertaking social responsibility and the loss of social reputation associated with the bad behaviour of partners (such as deliverers) into the model and adds social benefit ( $U$ ) to the objective function of the revenue-sharing contract. Then, platform enterprises encourage and restrict the behaviour of deliverers through the reward or punishment factor $(\beta)$. According to the analysis of the above model, there is no difference between the response function of optimal pricing to service level when the goal of platform enterprises is to maximize their comprehensive benefit and maximize shortterm economic returns. Therefore, this part focuses on the analysis of the optimal level of deliverers' efforts and the commitment service level in the platform.

Platform enterprises expect deliverers to work hard, but they do not want their efforts to exceed the normal level, which will lead to illegal behaviours. Therefore, the expectation of the platform is $e_{\max \left(\pi_{2}\right)}^{*}<e^{0}$, that is:

$\frac{(1-\emptyset) 2 \delta+(1-\emptyset+c) \emptyset r}{(1-\emptyset)\left(2 k_{2}-\emptyset r^{2}\right)} \leq-\frac{b}{2 a}$.

Thus, $\delta \leq \frac{-2 a \emptyset r(1-\emptyset+c)-\left(2 k_{2}-\emptyset r^{2}\right) b(1-\emptyset)}{4 a}$.

Under the centralized decision-making scenario, when $\varepsilon=0$ and $\theta=1$ :

$e_{\max (\pi)}^{*}=\frac{2 b+r(1-c)}{2 k-4 a-r^{2}}$.

In the case of $\varepsilon=0$ and $\theta=1$, when $e_{\max (\pi)}^{*}=e_{\max \left(\pi_{2}\right)}^{*}$, the optimal coordination of the supply chain can be achieved. Compared with the optimal service effort in the context of profit maximization, the following relationship exists between $e_{\max \left(\pi_{2}\right)}^{*}$ and $e_{\max \left(R_{2}\right)}^{*}$ :

$e_{\max \left(\pi_{2}\right)}^{*}=e_{\max \left(R_{2}\right)}^{*}+\frac{c \emptyset r+2 \delta(1-\emptyset)}{\left(2 k_{2}-\emptyset r^{2}\right)(1-\emptyset)}$.

To ensure that $e_{\max \left(\pi_{2}\right)}^{*} \geq e_{\max \left(R_{2}\right)}^{*}$, based on the Theorems 2 and 4, the platform should keep the awards coefficient is:

$\delta>-\frac{c \emptyset r}{2(1-\emptyset)}$.

This shows that the platform can manage deliverers' behaviours through setting a reasonable reward factor $(\delta)$. When $-\frac{c \emptyset r}{2(1-\emptyset)}<\delta \leq \frac{-2 a \emptyset r(1-\emptyset+c)-\left(2 k_{2}-\emptyset r^{2}\right) b(1-\emptyset)}{4 a}$, the optimal level of service selected by the deliverers is constrained within a reasonable range, which can effectively reduce the risk of illegal behaviours.

Thus, the award coefficient paid by the platform to the deliverers will be in the following range:

$-\frac{c \emptyset r}{2(1-\emptyset)}<\delta \leq \frac{-2 a \emptyset r(1-\emptyset+c)-\left(2 k_{2}-\emptyset r^{2}\right) b(1-\emptyset)}{4 a}$.

Theorem 6 Considering CSR, the platform guides and regulates deliverers to actively improve the service level within the legal scope by adding a contingent reward factor $\beta=\delta e$ into the revenue-sharing contract. And when the reward coefficient $(\delta)$ is in the range of $\left[-\frac{c \emptyset r}{2(1-\emptyset)}, \frac{-2 a \emptyset r(1-\emptyset+c)-\left(2 k_{2}-\emptyset r^{2}\right) b(1-\emptyset)}{4 a}\right]$, the optimal efforts of the deliverers are larger than those in the first scenario $\left(e_{\max \left(R_{2}\right)}^{*}\right)$ and less than the critical turning point of social benefit maximization $\left(e^{0}\right)$; exists the relationship $e_{\max \left(R_{2}\right)}^{*} \leq e_{\max \left(\pi_{2}\right)}^{*} \leq e^{0}$.

If the service level continuously improves, the probability of deliverers behaving illegally will increase. Therefore, platform enterprises adopt the punishment factor $(\delta)$ to constrain the behaviour of the deliverers. At this time, for the 
Table 2 Decision-making with the goal of maximizing profits or considering CSR

\begin{tabular}{|c|c|c|c|c|}
\hline Scenario & Optimal decision & Centralized decision-making & Decentralized decision-making & $\begin{array}{l}\text { Conditions } \\
\text { of optimal } \\
\text { coordination }\end{array}$ \\
\hline \multirow[t]{4}{*}{$\begin{array}{l}\text { Economic revenue } \\
\text { maximization }\end{array}$} & Pricing of platform & $P_{\max (R)}^{*}=\frac{1+r S+c}{2}$ & $P_{\max \left(R_{1}\right)}^{*}=\frac{(1-\emptyset)(1+r S)+c}{2(1-\emptyset)}$ & $\begin{array}{l}\emptyset=\frac{2 k_{2}(1-c)}{2 k-r^{2} c} \\
\varepsilon=0 ; \theta \stackrel{1}{=} 1\end{array}$ \\
\hline & $\begin{array}{l}\text { Service-level commitment by } \\
\text { platform }\end{array}$ & $e_{\max (R)}^{*}=\frac{r(1-c)}{2 k-r^{2}}$ & $e_{\max \left(R_{1}\right)}^{*}=\frac{r(1-\emptyset-c)}{2 k_{1}-r^{2}(1-\emptyset)}$ & \\
\hline & Efforts of deliverers & & $e_{\max \left(R_{2}\right)}^{*}=\frac{\emptyset r}{\left(2 k_{2}-\emptyset r^{2}\right)}$ & \\
\hline & $\begin{array}{l}\text { Deliverers' efforts in the situation of } \\
\text { optimal coordination }\end{array}$ & $\frac{\emptyset \sqrt{2 k_{1}}}{2\left(k_{2}-k_{1} \emptyset\right)}$ & & \\
\hline \multirow[t]{4}{*}{ Considering CSR } & Pricing of platform & $P_{\max (\pi)}^{*}=\frac{1+r S+c}{2}$ & $P_{\max \left(\pi_{1}\right)}^{*}=\frac{(1-\emptyset)(1+r S)+c}{2(1-\emptyset)}$ & $\begin{array}{l}\emptyset=\frac{2\left(r^{2}-k_{2}\right)}{r^{2}} \\
\varepsilon=0 ; \theta=1\end{array}$ \\
\hline & $\begin{array}{l}\text { Service-level commitment by } \\
\text { platform }\end{array}$ & $e_{\max (\pi)}^{*}=\frac{2 b+r(1-c)}{2 k-4 a-r^{2}}$ & $e_{\max \left(\pi_{1}\right)}^{*}=\frac{2(b-\delta)+(1-\emptyset)-c) r}{2 k_{1}-4 a-(1-\emptyset) r^{2}}$ & \\
\hline & Efforts of deliverers & & $e_{\max \left(\pi_{2}\right)}^{*}=\frac{(1-\emptyset) 2 \delta+(1-\emptyset+c) \emptyset r}{(1-\emptyset)\left(2 k_{2}-\emptyset r^{2}\right)}$ & \\
\hline & Contingent reward coefficient $(\delta)$ & {$\left[-\frac{c \emptyset r}{2(1-\emptyset)}, \frac{-2 a \emptyset r(1-\emptyset+c)-\left(2 k_{2}-\emptyset r^{2}\right) b(1-\emptyset)}{4 a}\right]$} & & \\
\hline
\end{tabular}

deliverer, the optimal decision is to choose a normal level of effort and service. In this way, platform enterprises restrict the level of deliverers' efforts to a reasonable range by means of reward or punishment factors, and deliverers pursue their own profit maximization without damaging the social reputation of the platform.

If the revenue-sharing contract considering social responsibility can make the agent (deliverers) maximize the principal's (platform or supply chain) revenue while pursuing his own revenue maximization, then the coordination mechanism of the contract is effective. Furthermore, when the optimal choice of decentralized decision is equal to the optimal choice of centralized decision, the supply chain reaches the optimal coordination state. In the scenario two, when $\varepsilon=0$ and $\theta=1$, suppose $e_{\max (\pi)}^{*}=e_{\max \left(\pi_{2}\right)}^{*}$, get:

$\delta_{1}=\frac{[2 b+(1-c) r](1-\emptyset)\left(2 k_{2}-\emptyset r^{2}\right)+(1-\emptyset+c)\left(2 k-4 a-r^{2}\right) \emptyset r}{2(1-\emptyset)\left(2 k-4 a-r^{2}\right)}$.
Theorem 7 Considering CSR and with the goal to maximize the long-term comprehensive benefit, when the proportion of revenue sharing between the platform and deliverer is equal to $\frac{2 r^{2}-2 k_{2}}{r^{2}}$ in the case of $\varepsilon=0$ and $\theta=1$, supply chain achieves optimal coordination and in the optimal coordination state.

\section{Coordination mechanism and benefits comparison based on the revenue-sharing contract}

The coordination mechanism based on the revenue-sharing contract in two different situations of profit maximization and considering CSR is summarized in Table 2. In the first scenario, with revenue-sharing contract, the condition for the supply chain to achieve optimal coordination is
Let $\delta_{1}=\delta_{2}$, get:

$\emptyset=\frac{2 r^{2}-2 k_{2}}{r^{2}}$.

$$
\begin{aligned}
& \text { And suppose } e_{\max \left(\pi_{1}\right)}^{*}=e_{\max \left(\pi_{2}\right)}^{*} \text {, get: } \quad \emptyset=\frac{2 k_{2}(1-c)}{2 k-r^{2} c} \text { in the case of } \varepsilon=0 \text { and } \theta=1 \text {. And in the second } \\
& \delta_{2}=\frac{2 b(1-\emptyset)\left(2 k_{2}-\emptyset r^{2}\right)+[(1-\emptyset)(1-c)+\emptyset c] 2 k_{2} r-(1-\emptyset+c)(2 k-4 a) \emptyset r}{2(1-\emptyset)\left(2 k-4 a-r^{2}\right)} .
\end{aligned}
$$

scenario, with revenue-sharing contact considering CSR, the condition for the supply chain to achieve optimal coordination is $\emptyset=\frac{2\left(r^{2}-k_{2}\right)}{r^{2}}$ in the case of $\varepsilon=0$ and $\theta=1$. In addition, the platform guides deliverers' behaviours to improve the service level within the legal scope using a contingent reward factor $\beta=\delta e$. When the reward coefficient is in the 
Table 3 Benefits' comparison

\begin{tabular}{llll}
\hline Decision-making & Economic perspective & Considering CSR & Benefits comparison \\
\hline Centralized & $R=(P-c) D-C(S)$ & $\pi=(P-c) D-C(S)+U$ & If $U>0, \pi>R$ \\
Decentralized & $R_{1}=((1-\emptyset) P-c) D-C_{1}(S)$ & $\pi_{1}=((1-\emptyset) P-c) D-C_{1}(S)+U-\beta(e)$ & If $U>\beta, \pi_{1}>R_{1}$ \\
& $R_{2}=\emptyset P \times D-C_{2}(S)$ & $\pi_{2}=\emptyset P \times D-C_{2}(S)+\beta(e)$ & If $\beta>0, \pi_{2}>R_{2}$ \\
\hline
\end{tabular}

range of $\left[-\frac{c \emptyset r}{2(1-\emptyset)}, \frac{-2 a \emptyset r(1-\emptyset+c)-\left(2 k_{2}-\emptyset r^{2}\right) b(1-\emptyset)}{4 a}\right]$, the deliverers' effort is within the reasonable range expected by the platform operator $\left(e_{\max \left(R_{2}\right)}^{*} \leq e_{\max \left(\pi_{2}\right)}^{*} \leq e^{0}\right)$. By designing reasonable proportion of revenue sharing and a contingent reward factor, supply chain achieves effective coordination based on revenue-sharing contract.

At the same time, the benefits' comparison of the two different scenarios is shown in Table 3. As long as the social benefits associated with the platform's social responsibility are not negative, the overall benefits of the supply chain will be improved $(U>0, \pi>R)$, and the comprehensive benefits of the platform will be larger than the short-term economic returns $\left(U>\beta, \pi_{1}>R_{1}\right)$. If the rewards paid by the platform to the deliverers are lower than its own social benefits, then the deliverers can improve their returns $\left(\pi_{2}>R_{2}\right)$ through gaining positive rewards $(\beta>0)$ without illegal action. Therefore, from a long-term perspective, to consider the comprehensive benefits associated with social responsibility, the supply chain can achieve multiple win-win results for all parties.

\section{Managerial insights}

The main findings of this study reveal that using a revenuesharing contract considering CSR, the supply chain under the sharing economy can resolve the social responsibility dilemma caused by the illegal behaviour of service deliverers with the goal of long-term comprehensive benefit maximization and realize multiple win-win situations by adding a contingent reward factor into the traditional revenue-sharing contract.

In recent years, more and more attention has been paid to the social responsibility of platform. In its social responsibility report, Meituan disclosed deliverers' practices of social responsibility, such as helping to save lives, putting out fires, helping lost children return to their homes, participating in typhoon, rainstorm, mudflow and other disaster rescue or post disaster reconstruction, etc. In addition to reporting on these practices, Meituan awarded the deliverer the title of "Examplary Rider", issued certificates, and gave cash rewards, calling on other riders to learn from him. Didi platform also provides recording proof for drivers who save babies, and issues bonus for just cause, and gives red envelope rewards to drivers who provide holiday services during the Spring Festival, so as to encourage drivers to pay attention to social needs and practice social responsibility. The above platform enterprises' rewards for riders or drivers can guide the behaviour of service providers to some extent. Although, in these two cases, a unified management system has not been yet formed, it is enough to show that the platform enterprises can flexibly adjust the service-level evaluation and regulate the behaviour of the service providers from the perspective of social responsibility. The conclusion of this study will provide a theoretical basis for these platforms to improve the management of service providers and to upgrade individual reward behaviour to a unified management system.

Based on our study's main findings regarding managerial insights and practical implications, we propose some management suggestions for sharing economy platforms and policy inspiration for regulatory authority:

1. Platform enterprises need to change the perception of CSR, no longer to fulfill social responsibility as a oneway devotion of charity, but from the management concept of identity, enterprises can create business value and promote the sustainable development of enterprises by helping to solve or solving social problems independently.

2. Treating service deliverers as cooperative members of the supply chain, platform should pay attention to the loose cooperative relationship between organizations and individuals, and design effective mechanisms to manage the behaviour of loose partners; for example, setting contingent reward factors to restrict the legitimacy of their behaviours.

3. Platforms operators can improve the estimation algorithm of service level commitment by adding a threshold judgement of normal delivery time to restrict service deliverer's service efforts within the legal scope.

4. Platform can change the way it promises the service level to consumers and adjust the simple expected delivery time to the expected service time under normal traffic conditions. In terms of delivery time commitment, flexible time should be reserved to avoid the pressure of the continuous iterative convergence of the algorithm leading to a continuous increase in consumer expectations beyond the legal time. 
5. Platforms should adopt multiple evaluation methods for deliverers instead of a single timely delivery rate and pay more attention to service quality than service efficiency. For example, multiple assessment indicators are adopted, and the reasonable time and safety index of service delivery are comprehensively considered to reward. They should even take the initiative to guide the deliverers to bear social responsibility and publicize behaviours that have a good social impact.

6. For government, enhancing policy publicity and public opinion guidance can help enterprises change their ideas, re-recognize the value of social responsibility, guide platform enterprises in sharing economy to pursue long-term interests and sustainable development, and avoid vicious competition for short-term interests.

7. Supervision should be strengthened. Regulatory authorities should pay more attention to the new problems brought by the new technology application and business mode, promote the development of collaborative governance, explore the use of information technology to solve the social responsibility problems brought by the application of information technology, and pay more attention to the algorithm ethics of sharing economy platform, such as the algorithm of Meituan platform's commitment service level.

8. To provide preferential policies and social security support for enterprises of sharing economy and individual providers of sharing services, such as riders, so as to create a good business environment. For example, provide tax incentives or technical training services for innovative enterprises, provide necessary social security for individual service providers such as riders, eliminate their worries, and avoid the occurrence of short-term economic behaviours.

\section{Conclusions}

Under the constraint of the service-level commitment in the supply chain of the sharing platform, service deliverers (riders) may take illegal actions to maximize their own revenue, thus damaging the long-term comprehensive benefits of platform enterprises. The more sensitive customers are to the service delivery time, the greater the elasticity of demand/service, and the more likely the service deliverers try to improve the service level by shortening the delivery time. With the reduction of the average service delivery time, the service level promised by the platform will gradually be improved. Even if the supply chain is in the optimal coordination state, the revenue sharing paid by the platform to the deliverers is not enough to motivate deliverers to avoid violations of traffic regulations. In this situation, deliverers who aim to maximize their own revenue are likely to take illegal actions to increase the number of orders and obtain higher revenue. Therefore, under the revenue-sharing contract with economic benefit maximization as the objective function, even if the optimal coordination of the supply chain can be achieved, the social dilemma caused by the deliverer's illegal behaviour is not solved. To address the above difficulties, this study examines and reconstructs the original revenue-sharing contract from the perspective of social responsibility and adds social benefits to the original objective function. Platform enterprises undertake or perform social responsibility to promote their social reputation, which has long-term benefits for them, but service deliverers' violations will damage the social reputation of the platform. To incentivize service deliverers to make reasonable efforts, the contingency reward factor is added to the objective function. The results show that the sharing economy platform can adjust deliverers' behaviour through the reward factor $\delta$, and the level of effort chosen by the deliverers is limited to a reasonable range, which to some extent reduces the probability of violations.

The contribution is that the comprehensive benefit from the perspective of social responsibility is introduced into the revenue-sharing contract mechanism, and the revenue function is reconstructed. By adding a contingency reward factor to the objective function, the platform enterprise realizes a reasonable constraint on service deliverers' behaviours. Reasonable contingency factors can effectively reduce the moral hazard behaviour of service providers. This approach breaks through the limitations of the supply chain coordination mechanism that considers only economic benefits. It brings new insights on coordination of supply chain in the sharing economy and identifies new direction for future research on CSR. In practice, the findings provide useful ideas and a theoretical basis for platform enterprises to change the dilemma of social responsibility by improving the algorithm of the system and reshaping the cooperative mechanism of their partners, and provide managers of platform with suggestions for regulating the behaviour of partners and balance the economic and social benefits.

There are also some limitations in this study, such as not analyzing the impact of the platform on the optimal decision-making and coordination associated with punishments for service delivery over the promised time. And the cyclical effect of social responsibility on demand is not considered in the demand function. In addition, this study only gives some examples of sharing economy platform rewarding service providers to practice social responsibility, but has not carried out in-depth case studies to test the application of the optimal coordination scheme proposed in this study. Finally, in reality, there are many other factors that influence the service level and the deliverers' effort besides those mentioned in this paper, which may need multi-dimensional research through empirical test. Future research will focus on the above issues. 


\section{Appendix}

The logic proof of relationship between service level $(S)$ committed by the platform and the effort $(e)$ of deliverers is as follows.

We suppose that:

1. the average delivery time of service is $\bar{t}$;

2. the shorter the delivery time, the higher the level of service, and the commitment service level infinitely close to $N$ which is an infinite value:

$$
\lim _{\bar{t} \rightarrow 0} S \rightarrow N \text {. }
$$

3. the higher the level of efforts, the shorter the delivery time, and the effort of deliverers infinitely close to $E$ which is an infinite value:

$$
\lim _{\bar{t} \rightarrow 0} e \rightarrow E \text {. }
$$

In our research, we use delivery time to measure service level. In the sharing economy platform, the commitment service level is determined by algorithm which estimates the average delivery time of a service order based on the historical data of delivery time. Therefore, the function of $S$ is expressed as:

$S=N-f \bar{t} \quad f>0$.

To shorten the delivery time, deliverers need to pay more efforts. Each deliverer improves his or her level of effort to shorten the service delivery time, and the average delivery time will been shortened. Therefore, the relationship between $e$ and $\bar{t}$ can be expressed as:

$e=E-m \bar{t} \quad m>0$.

Based on the function of (59) and (60), we get:

$S=\frac{f}{m} e+\left(N-\frac{f}{m} E\right)$.

Suppose $\frac{f}{m}=\theta$ and $\left(N-\frac{f}{m} E\right)=\varepsilon$, and therefore, the relationship of $S$ and $e$ can be expressed as:

$S=\theta e+\varepsilon$.

When the marginal improvement of service level is equal to the deliverer's marginal effort, the improvement of deliverer's effort level will promote the platform's service level to the same extent. Therefore, suppose $f=m$, then $N=E$; exists $\theta=1$ and $\varepsilon=0$.
Author contributions JG is in charge of investigation, resources, and writing - original draft. YG (corresponding author) is in charge of conceptualization, modeling and methodology, formal analysis, writingoriginal draft and writing - review and editing, funding acquisition, and project administration.

Funding This work was supported by the Funding project of Beijing Philosophy and Social Science Research Program (17BGL033).

Availability of data and materials Not applicable.

Code availability Not applicable.

\section{Declarations}

Conflict of interest The authors declare no conflicts of interest. The funders had no role in the design of the study; in the collection, analyses, or interpretation of data; in the writing of the manuscript; or in the decision to publish the results.

Ethical approval This manuscript has not been published or presented elsewhere in part or in entirety and is not under consideration by another journal. All study participants provided informed consent, and the study design was approved by the appropriate ethics review board. We have read and understood your journal's policies, and we believe that neither the manuscript nor the study violates any of these.

Open Access This article is licensed under a Creative Commons Attribution 4.0 International License, which permits use, sharing, adaptation, distribution and reproduction in any medium or format, as long as you give appropriate credit to the original author(s) and the source, provide a link to the Creative Commons licence, and indicate if changes were made. The images or other third party material in this article are included in the article's Creative Commons licence, unless indicated otherwise in a credit line to the material. If material is not included in the article's Creative Commons licence and your intended use is not permitted by statutory regulation or exceeds the permitted use, you will need to obtain permission directly from the copyright holder. To view a copy of this licence, visit http://creativecommons.org/licenses/by/4.0/.

\section{References}

1. Bharadwaj N, Kumar P, Arkatkar SS, Joshi G (2020) Deriving capacity and level-of-service thresholds for intercity expressways in India. Transp Lett 12(3):182-196

2. Carter CR, Easton PL (2011) Sustainable supply chain management: evolution and future directions. Int J Phys Distrib Logist Manag 41(1):46-62

3. Dong XZ, Ma SS, Chen XK (2019) Study on incentive mechanism of customer knowledge co-creation-principal-agent model under uncertainty. Math Pract Theory 24:83-89

4. Gao SY, Zhang Y, Ma XH (2019) Quantitative analysis of the connotation and research field of sharing economy. J Tech Econ Manag 09:98-102

5. Gupta S, Garg H, Chaudhary S (2020) Parameter estimation and optimization of multi-objective capacitated stochastic transportation problem for gamma distribution. Complex Intell Syst 6:651-667

6. Heydari J, Rafiei P (2020) Integration of environmental and social responsibilities in managing supply chains: a mathematical modeling approach. Comput Ind Eng. https://doi.org/10.1016/j.cie. 2020.106495 
7. He ZG, Shuai B, Zhang Y (2004) Research on service standards of logistics enterprises. Soft Sci 05:93-96

8. He Z, Wang JF, Li B, Yang XH (2017) Trust incentive model of information sharing of service supply chain. Technoecon Manag Res 11:57-61

9. Hosseini-Motlagh SM, Ebrahimi S, Zirakpourdehkordi R (2020) Coordination of dual-function acquisition price and corporate social responsibility in a sustainable closed-loop supply chain. J Clean Prod. https://doi.org/10.1016/j.jclepro.2019.119629

10. Hu JY, Liu YL, Yuen TWW (2019) Do green practices really attract customers? The sharing economy from the sustainable supply chain management perspective. Resour Conserv Recycl 149:177-187

11. Ishfaq R, Raja U (2020) Effectiveness of frequent inventory audits in retail stores: an empirical evaluation. Int J Logs Manag 31(1):21-41

12. Jiang M, Li HX, Liu DH (2020) Repeated game analysis of supply chain governance structure of customized products based on e-commerce B2B platform. Oper Res Manag Sci 29(08):45

13. Johari M, Hosseini-Motlagh SM (2020) Coordination contract for a competitive pharmaceutical supply chain considering corporate social responsibility and pricing decisions. Rairo Oper Res 54(5):1515-1535

14. Johari M, Hosseini-Motlagh SM (2019) Coordination of social welfare, collecting, recycling and pricing decisions in a competitive sustainable closed-loop supply chain: a case for lead-acid battery. Ann Oper Res. https://doi.org/10.1007/s10479-019-03292-1

15. Lai YX (2020) Takeaway rider stuck in the system. People 8:70-79

16. Li SY, Li ML, Zhou N (2020) Pricing and coordination in a dualchannel supply chain with a socially responsible manufacturer. PLoS ONE 15(7):e0236099. https://doi.org/10.1371/journal.pone. 0236099

17. Liu Y, Liu ZY, Ren WW (2020) A coordination mechanism through relational contract in a two-echelon supply chain. J Retail Consum Serv. https://doi.org/10.1016/j.jretconser.2020.102156

18. Li D, Ma C, Sun Q, Lin H (2019) Research on outsourcing supply chain game model based on corporate social responsibility. $\mathrm{J}$ Qingdao Univ (Nat Sci Ed) 32(03):110-122

19. Guoyan $\mathrm{Li}, \mathrm{Nan} \mathrm{Li}$ (2016) The incentive model of tacit knowledge transfer in start-up social network_— based on reputation effects model. Sci Technol Prog Policy 07:139-143

20. Li SJ, Zhu ZB, Huang LH (2009) Supply chain coordination and decision making under consignment contract with revenue sharing. Int J Prod Econ 120(1):88-99

21. Li TN, Luo JH (2013) The incentive-restricted mechanism based on a two-stage moral risk model. Syst Eng 02:84-93

22. Liu ML, Dan B, Ma SX (2020) Optimal decision and coordination of fresh food supply chain considering fresh keeping efforts and value-added services. Chin J Manag Sci 08:76-88

23. Liu Y, Xu Q, Liu ZY (2020) A coordination mechanism through value-added profit distribution in a supply chain considering corporate social responsibility. Manag Decis Econ 41(4):586-598

24. Long XF, Ge JL, Shu T, Liu CX (2020) Production decision and coordination mechanism of socially responsible closed-loop supply chain. Complex Econ Bus. https://doi.org/10.1155/2020/9095215

25. Luo S, Liu SL (2020) Rental housing "formaldehyde gate": principal-agent model under the information asymmetry dilemma. Chongqing Soc Sci 305(04):109-120. https://doi.org/10.19631/j. cnki.css.2020.004.012

26. Mahdiraji HA, Hafeez K, Jafarnejad A (2020) An analysis of the impact of negative CSR 'forced labour' parameter on the profitability of supply chain contracts. J Clean Prod 271:122274. https:// doi.org/10.1016/j.jclepro.2020.122274

27. Naik A, Satapathy SC (2020)A comparative study of social group optimization with a few recent optimization algorithms. Complex
Intell Syst 36(05):87. https://doi.org/10.19744/j.cnki.11-1235/f. 2020.0072

28. Niu BZ, Li QY, Chen L (2020) Exclusive vs. competitive retailing: overseas vaccine supplier's channel selection considering profit and social responsibility objectives. Comput Ind Eng. https://doi. org/10.1016/j.cie.2020.106499

29. Pagell M, Wu ZH (2009) Building a more complete theory of sustainable supply chain management using case studies of 10 exemplars. J Supply Chain Manag 2:37-56

30. Peng HG (2019) Basic textbook on corporate social responsibility. China Overseas Chinese Press (2):5-6 ISBN:978-7-5113-7956-6

31. Ran AP, Zhou YR (2020) Research on the optimal price and expected revenue of crowdsourcing logistics platform servicedynamic price model analysis considering the influencing factors of platform subsidy level. Price Theory Pract 430(04):136. https:// doi.org/10.19851/j.cnki.CN11-1010/F.2020.04.125

32. Shi XT, Chan HL, Dong CW (2020) Impacts of competition between buying firms on corporate social responsibility efforts: does competition do more harm than good? Transp Res Part E: Logist Transp Rev. https://doi.org/10.1016/j.tre.2020.101985

33. Tian G, Liu JJ, Gong Y (2020) Multinational companies' coordination mechanism for extending corporate social responsibility to Chinese suppliers. J Clean Prod 267:121896. https://doi.org/10. 1016/j.jclepro.2020.121896

34. Wang Q, Xie CY, Cui YW (2018) Quality incentives based on newsvendor model under asymmetric information. Manag Rev 30(06):227-237. https://doi.org/10.14120/j.cnki.cn11-5057/f.2018. 06.019

35. Wang ZZ, Wang MZ, Liu WW (2020) To introduce competition or not to introduce competition: an analysis of corporate social responsibility investment collaboration in a two-echelon supply chain. Transp Res Part E: Logist Transp Rev. https://doi.org/10. 1016/j.tre.2019.11.006

36. Xiao HJ (2020) The reflection and transcendence of the creating shared value as a corporate social responsibility paradigm. Manag World 36(05):87-1. https://doi.org/10.19744/j.cnki.11-1235/f. 2020.0072

37. Xiao T, Xu T (2013) Coordinating price and service level decisions for a supply chain with deteriorating item under vendor managed inventory. Int J Prod Econ 145(2):743-752

38. Zhang GJ, Chen XB, Liu RJ (2018) Analysis and motivation of multi-agent behaviour relationship based on principle agent models of neutrality. Competition and cooperation. Chin J Manag 09:1402-1410

39. Zhang J, Gou QL, Liang L (2013) Supply chain coordination through cooperative advertising with reference price effect. Omega Int J Manag Sci 2:345-353

40. Zhang LH, Wang JG, You JX (2015) Consumer environmental awareness and channel coordination with two substitutable products. Eur J Oper Res 241(1):63-73

41. Zhang W (2020) Study on two-stage game model of shared platform under bilateral moral risk. Econ Forum 02:127-136

42. Zhang Z, Xu H, Liu Z, Fang Y (2020) Implications for pure profit, environmental impact and social welfare in a socially responsible supply chain. Kybernetes. https://doi.org/10.1108/K-12-2019-0852

43. Zheng SG, Su DH, Wang SY, Shang W (2020) Research on reward income sharing model of live streaming platforms. Syst Eng Theory Pract 40(05):1221-1228

Publisher's Note Springer Nature remains neutral with regard to jurisdictional claims in published maps and institutional affiliations. 